\title{
Care of plantar ulcerations: comparing applications, materials and non-casting
}

\author{
MARIAN KAPLAN \& R H GELBER \\ Hansen's Disease Clinic, Seton Medical Center, Daly City, \\ California, USA
}

Accepted for publication 9 September 1987

Summary We have reviewed our experience with plantar ulcer care in our population of 525 patients treated between 1982 and 1987. Patients were treated with standard plaster of Paris casts, alternative methods of casting, and without casting. Of the 24 patients who received casts, all healed, while 23 of the 30 patients healed without casting. The average healing time for those who were casted was $5 \cdot 6 \pm 2 \cdot 6$ weeks and for those uncasted, $8 \cdot 1 \pm 6 \cdot 6$ weeks $(P=0 \cdot 1)$. It was concluded that ulcers can heal without casting and that alternative casting procedures offer certain significant advantages. Such approaches are especially applicable to the current leprosy population being treated in the community and remaining ambulatory.

\section{Introduction}

Plantar ulceration, a direct consequence of insensitivity, is a frequent and serious complication in leprosy. Nonhealing neuropathic ulcers often become infected and, if they remain untreated, result in osteomyelitis and bony absorption, thus producing a deformed foot. A deformed foot is even more prone to ulceration. If this cycle of ulceration is repeated often enough, amputation may be necessary. Amputation can be avoided by prompt treatment to close the ulcer, medication to cure the infection, proper footwear for protection of the anaesthetic foot and education of the patient.

The traditional method of applying a plaster of Paris - total contact case (POP-TCC) has been described by others. ${ }^{1-7}$ Since 1982 we have had many patients at our clinic who have refused application of a TCC for various reasons, such as inability to use crutches while the cast dries, or living conditions necessitating climbing long flights of steps. The majority of today's leprosy patients are not being hospitalized but instead are working or going to school in either rural or urban areas. For them the appearance of a cast and the wearing of it are of ten an embarrassment and a hindrance. Thus an alternative to the traditional POP-TCC which would be lighter in weight and permit immediate ambulation without crutches would offer advantages that would enable us to convince some patients to accept casting. For this purpose we have examined several alternatives of both materials and methods of application. In this paper we will review our experience in the care of plantar ulcers in leprosy patients utilizing the standard POP cast, alternative casting procedures, and results obtained without casting. 
Table 1. Casting-theme and variations.

1 Traditional below knee plaster of Paris (POP) total contact cast (TCC).

Materials: Stockinette, orthopaedic felt, POP, board and walking heel or stirrup.

Application: To assist in cast removal orthopaedic felt is applied in a strip down the leg dorsum from top of cast to base of toes and a piece over each malleolus. Then a thin 'egg-shell' layer of POP is applied and moulded well into the leg, followed by supporting layers of POP and application of a board and walking heal or stirrup.

\section{Advantages}

a Materials are generally available.

b Cost is low.

c POP moulds well.

d Ulcerations usually heal without complications

\section{Disadvantages}

a Drying time is $24 \mathrm{~h}$ or longer.

b Some patients cannot use crutches during drying time.

c Walking heel puts cast close to ground thus getting it wt/dirty.

$\mathrm{d}$ Cast is thick and heavy.

e Cast is difficult to remove because it is not bivalved.

2 Total contact cast reinforced with Scotch Cast reinforcing strips.*

Materials: Stockinette, orthopaedic felt, POP, Scotch Cast reinforcing strips, walking device (board and heel or stirrups).

Application: Apply as for technique 1 substituting Scotch Cast reinforcing strip instead of POP immediately after 'egg-shell' layer, then complete cast with POP and walking device.

\section{Advantages}

a Drying time is slightly less.

b Cast is lighter and stronger.

c Materials are generally available.

d POP and Scotch Cast adhere well to each other.

e This variation has all the advantages of the traditional below knee TCC.

\section{Disadvantages}

a Crutches are still needed until the cast dries.

b Removal of cast is more difficult due to the hardness of the reinforcing material.

3 TCC 'egg-shell' of POP with surrounding cast padding and Scotch Cast to complete.

Materials: Stockinette, cast padding, POP, Scotch Cast, walking device.

Application: Over stockinette apply cast padding only to cover malleoli and any bony prominences. Apply 'egg-shell' layer of POP and mould into leg. Wrap thick layer of padding around 'egg-shell' layer and apply Scotch Cast using as many layers as needed for durability. Apply either heel or stirrup or supply patient with cast boot.

\section{Advantages}

a Patient can ambulate $\frac{1}{2} \mathrm{~h}$ after application of cast.

b Crutches are not needed.
Disadvantages

a It appears likely that ulcers do not heal as quickly. 
Table 1. Casting - theme and variations.

c Cast is light weight and strong.

$\mathrm{d}$ Walking device is not needed.

e Removal is simplified by bivalving the cast and cutting the 'egg-shell' layer with plastercutting scissors.

4 Orthopaedic padded cast using Scotch Cast only.

Materials: Stockinette, cast padding, Scotch cast, and cast boot.

Application: Apply several layers of cast padding over stockinette, then apply layers of Scotch cast to desired thickness for durability.

\section{Advantages}

a This has all the advantages of technique 3 .

\section{Disadvantages}

a Further breakdown at ulcer site was noted, possibly because padding holds drainage from the ulcer against the skin causing surrounding area to macerate.

\section{Shoe cast.}

Materials: Stockinette, cast padding, orthopaedic felt, POP, board and heel.

Application: Apply padding over stockinette at ankle if cast is to cover malleoli. Apply orthopaedic felt down front of foot for cast removal, then apply POP as a shoe with board and heel.

\section{Advantages}

a Application is not difficult.

b Cast is much higher than a below knee cast.

c Removal of cast is easy.

\section{Disadvantages}

a Cast can cause rubbed areas around the ankle.

b Even slight looseness can make ambulation unsafe.

\section{Scotch cast as a total contact cast.}

Materials: Stockinette, orthopaedic felt, Scotch Cast.

Application: Apply double layer of stockinette, then apply a thin strip of $\frac{1}{8}$ in thick orthopaedic felt down each side of the leg to cover malleoli and from below malleoli to base of the toes, as well as around leg at top of cast. Apply Scotch Cast in the same manner as POP total contact cast using palm pressure to mould. Walking device can be used or a cast boot.

\section{Advantages \\ Disadvantages}

a Cast is quick drying $\left(\frac{1}{2} h\right)$ and no crutches are

a Materials are more expensive. needed.

b Scotch cast is not available in all countries.

b Cast is light weight and strong.

c Application is not difficult.

d Removal is simplified by bivalving. 


\section{Materials and methods}

This report describes our experience with plantar ulcerations in our leprosy population of 525 patients treated from October 1982 to April 1987. In those years 56 casts were applied to 24 patients ( 16 male, 8 female), ages $14-65$ with an average age of 45.9 years. The casting techniques utilized are described in detail in Table 1. Technique 1, the traditional POP-TCC with walking heel or Böhlertype stirrup iron, was applied a total of 24 times to 16 patients. An unpadded POP-TCC has been an excellent means to hasten healing of plantar ulceration while permitting reasonable amounts of ambulation. The traditional method of applying a TCC employs POP as the casting material, with minimal padding used only for pressure areas and as an aid to cast removal. A walking device, board and heel or walking stirrup (Böhler-type iron) is applied and after complete drying of POP the patient may ambulate while healing of the ulcer progresses. Technique 2, POP cast with Scotch Cast (Orthopedic Products, St Paul, Minn, USA) reinforcing strip, was applied a total of 19 times to 9 patients; technique 3, POP 'eggshell' layer finished with Scotch Cast, was applied a total of 2 times to 1 patient; technique 4, Scotch Cast padded cast, was applied a total of 3 times to 3 patients; technique 5, a shoe cast of POP, was applied 1 time to 1 patient; and, technique 6, Scotch Cast as a TCC, was applied a total of 8 times to 3 patients (see Table 2).

All of the patients received, as part of the treatment plan, moulded shoes and insoles with instructions concerning shoe care and wearing time, gait and foot care. The patients' feet were measured and a POP mould for shoes was prepared before the first cast was applied, and, where possible, the shoes were adjusted before final fitting between cast changes, usually at the third week of casting.

Additionally in this report we describe our experience with 40 patients whose ulcers were treated without TCC. The reasons for not casting were: 1 , the patient was elderly and unsteady in ambulating; 2 , the patient ref used casting; 3 , the patient could not use the crutches necessary until the cast dried (due to clawed hands); 4 , the patient was already hospitalized either for the ulcer or other cause and was, at the time, non-weight bearing on bed rest; 5 , the patient had immediate amputation of the ulcerated foot; 6 , the ulcer was infected; and 7, the patient left the area immediately after ulcer evaluation.

When the patient was not casted, the ulcer was usually debrided, cleaned well, and dressed with a topical ointment and dry sterile dressing. The patients were then given dressings and instructions for

Table 2. Results of six techniques used for healing plantar ulcers.

\begin{tabular}{lcccc}
\hline & & & & \\
Technique used & $\begin{array}{c}\text { Patients } \\
\text { in sample }\end{array}$ & $\begin{array}{c}\text { Average time cast on } \\
\text { (weeks) }\end{array}$ & $\begin{array}{c}\text { Approx. cost } \\
\text { of materials } \\
\text { (US \$) }\end{array}$ \\
\hline 1 POP-TCC & 16 & $5 \frac{1}{2}$ & 16 & $20 \cdot 00$ \\
2 POP, SC Reinforcing & 9 & $5 \frac{1}{2}$ & 9 & $30 \cdot 00$ \\
3 POP, Padding \& SC & 1 & 4 & 0 & $20 \cdot 00$ \\
4 Ortho. Padded Cast & 3 & 5 & 1 & $35 \cdot 00$ \\
5 Shoe Cast of POP & 1 & 3 & 0 & $10 \cdot 00$ \\
6 SC-TCC & 3 & $7 \frac{1}{2}$ & 3 & $40 \cdot 00$ \\
\hline
\end{tabular}

Those who did not heal using Techniques 3, 4 and 5, were casted with another technique to achieve full healing. 
home care as well as being provided with moulded shoes and inserts. They were instructed to limit ambulation and, if possible and necessary, were given crutches and shown non-weight bearing gait. Antibiotics were prescribed if indicated. Surgical procedures such as bony debridement, grafting or amputation were done when conservative treatment failed.

One patient had bilateral ulcerations of long-standing without treatment and had to be casted for extended periods. A variety of techniques were used in applying casts to this patient. However, as the ulcers usually recurred within days of healing, this patient's problem was finally solved by a flap graft. Due to the length of time this patient was casted and recasted, he has been omitted from the statistics. However, because his case is illustrative of many of the most difficult problems conf ronting ulcer patients and resulted in a salutary outcome, we have decided to present this case in depth (see Results). Also presented is a short summary of a case which required amputation.

\section{Results}

We have treated 64 patients ( 40 male, 24 female, mean age 45.9 years) who had plantar ulcers. The average size of the ulcer at its widest part was $1.9 \mathrm{~cm}$ with a range of $0 \cdot 7-4.5 \mathrm{~cm}$. Of those $64,24 \mathrm{had}$ casts applied at least once; all of those casted healed completely. The initial casting in four patients did not result in complete healing. However, these patients were then casted with a different technique and achieved full healing. Of those 24 healed ulcers, casts were left on the patient for an average of 2.7 weeks, and reapplied an average of 1.8 times, resulting in an average time of healing of $5 \cdot 6 \pm 2 \cdot 6$ weeks.

Forty patients were treated without casting from October 1982 to April 1987. This group included 23 male and 17 female patients with an age range of 23 to 75 years (mean age 48 years). The size of the ulcers ranged from 1 to $5 \mathrm{~cm}$ with an average size of $1.6 \mathrm{~cm}$. Twenty-three ulcers were healed, 7 remain unhealed, and 10 were lost to follow-up (usually having moved out of the area). Thus of those who could be followed ( 30 patients) $22 \%$ did not heal. In those that eventually healed, healing time of 1 week to 28 weeks was required, an average healing time of $8 \cdot 1 \pm 6 \cdot 6$ weeks. Healing also occurred in those who had amputations (4). Two Symes amputations were required in patients with Charcot joints, one patient having a severely infected foot. Because of repeated infection and osteomyelitis two patients required toe amputations, one of the great toe and the other the fif th toe.

Of those casted, all ulcers were eventually healed, whereas of those not casted, 7 did not heal. Of the 7 who did not heal, 6 of those patients, when seen initially at our clinic, presented with the ulcer, claiming it had repeatedly healed and reopened over many years. Some of these patients have had repeated infections at the ulcer site. The time to healing in those casted compared to those not casted was not significantly different $(P=0 \cdot 1)$. The occurrence of breakdown of the ulcer after healing was not significantly different between those who were casted (10 out of 24$)$ and those who were not casted (10 out of 30$)$. For those who accepted TCC, the average time between healing and reoccurrence of ulceration at the same site was $9 \frac{1}{2}$ months, $\mathrm{SD} \pm 2.6$ months (range: 1-24 months), whereas for those who were not casted the average time was $10 \frac{1}{2}$ months, $\mathrm{SD} \pm 6 \cdot 6$ months (range: $1 \frac{1}{4}-27$ months). The time to breakdown in the casted versus those not casted was not different $(P=0 \cdot 2)$.

Using techniques 1 and 2, healing time was similar, or about $5 \frac{1}{2}$ weeks. Few complications developed during wearing time. In the single patient treated by two applications of technique 3 treatment was discontinued after a total of 4 weeks as the ulcer appeared to be increasing in size and macerating, possibly due to the longer drying time of the POP layer with padding applied around it. Using technique 4, one patient had complete healing in 3 weeks but 2 other patients had only minimal healing in 6 weeks. With technique 5 , the cast became loose and the patient removed it at home. At his request, it was discontinued. On one patient not included in the statistics, using technique 5 there was some healing of the ulcer after 3 weeks but as the cast caused rub wounds around the ankle, it was discontinued. Technique 6 was tried for the first time on a patient who was 
able to return often to the clinic for monitoring. The first application was removed after 6 days to evaluate skin condition and ulcer size. As the patient's skin was not reddened on any area and as the ulcer had some healing evident, the cast was reapplied in the same manner as the first one. When the second application was removed 16 days later, the ulcer was pin-hole size and the skin was in excellent condition. The second patient was noncompliant, insisting on walking on a still-wet POPTCC. Although there was some healing on removal of the cast, there was a rub ulcer on the medial malleolus. A SC-TCC was applied and removed 7 days later. The skin of his leg and foot was in excellent condition and the ulcers healed to where another cast was not necessary. (Full healing occurred within 1 week while the patient ambulated with moulded shoes.) The third patient had a very deep, large (approximately $3 \mathrm{~cm}$ ) ulcer. The first and second SC-TCC applications were each removed after 1 week. After the second week, the skin around the ulcer was macerated; therefore, the cast was not immediately reapplied. Instead, the patient used a nonweight bearing crutch gait while ambulating for 3 days and changing the dressing daily to keep the ulcer and surrounding area dry. After 3 days the skin returned to normal and the ulcer was clean. Petrolatum was rubbed on the surrounding skin but not on the ulcer and a third SC-TCC was applied for 2 weeks. Presently, the ulcer is pin-hole size af ter $7 \frac{1}{2}$ weeks of casting and there is no need for further casting. The patient will have drop-foot surgery shortly to decrease the chances of reulceration.

Included here are summaries of two patients, one requiring amputation and one whose ulcer was healed without recurrence by means of a flap graft.

\section{AMPUTATION}

In July 1984 a 44-year-old male who had been lost to follow-up for many years attended the clinic with infected right foot plantar ulceration. Skin lesions clinically and histologically demonstrated relapsed lepromatous leprosy. The ulcer was approximately $5 \times 12 \mathrm{~cm}$ in length on the plantar surface and extended $0 \cdot 5-2.5 \mathrm{~cm}$ deep. The entire foot was inflamed, oedematous and malodorous. The patient was septic and had a fever (temperature $39 \cdot 3^{\circ} \mathrm{C}$ ) and chill. He stated the ulcer, which was nonhealing for 4 to 5 years, had been inf ected for 6 months but that he had only felt sick for the last 2 weeks. He was immediately hospitalized and after several days of treatment he was well enough to commence nonweight-bearing crutch gait training in preparation for the amputation of his foot. In August he had a partial amputation at the level of the forefoot, and the wound was left open to drain for 2 weeks. A second revision of the Symes amputation was then completed and the patient was hospitalized for $5 \frac{1}{2}$ weeks following surgery. During that time a prosthesis was supplied and ambulation progressed well. His stump to date remains in excellent condition and he has returned to his employment as a truck driver and labourer.

\section{FLAP GRAFT}

In September 1983, a 63-year-old male presented with bilateral plantar ulcerations (the right foot had 2 ulcers of approximately $3 \mathrm{~cm}$ each and the left foot had 1 ulcer approximately $1 \frac{1}{2} \mathrm{~cm}$ ) which he stated were recurrent for 20 years. In the remaining months of 1983 his right foot was casted 8 times (frequency of cast changes was due to heavy exudate from the ulcers). In January 1984, the cast was applied 4 times resulting in healing to pin-point size. At that time a decision was made to attempt to heal the left foot while the patient wore a moulded shoe on the right. Between February and May 1984 the left leg was casted 7 times, resulting in complete healing. To date (June 1987) the ulcer has not recurred on the left.

As the right foot ulcer continued to increase in size, a cast was once again applied and between July 1984 and March 1985 his right foot was casted 9 times with intervals when the patient ref used casting for personal reasons and, instead, used crutches. In early March 1985, he slipped while climbing a ladder and deeply cut his fifth toe. The cast was removed and the toe was surgically debrided, then splinted and bandaged. The patient was then nonweight-bearing on crutches for 
1 month. All ulcers and the toe appeared healed at that time. Breakdown occurred within 2 weeks of full ambulation and between April and May 1985 a cast was applied 6 times without effecting healing.

A decision was thus made to have a surgical flap procedure carried out. This was done in June 1985. However, the flap became infected and a second procedure was done in August 1985. In December 1985 the patient returned from a trip with an ulcerated blister over a deep bursa, above the grafted area. This was permitted to commence healing using non weight-bearing crutch gait. Then 3 stitches were taken to fully close the skin. From March 1986 to present (April 1987) the right foot has remained healed, and the patient ambulates well using moulded shoes and insert.

\section{Discussion}

Peripheral neuropathy of the lower extremity which involves only sensory loss without motor impairment can still be a debilitating problem. Preventing plantar ulceration involves a lifetime of caution in matters which the sensory-privileged person cannot imagine. Often a break in the skin is not noticed until it is large and possibly smells from inf ection or until blood is noticed on the socks or insoles of the shoe. Unless the patient has become aware of the need to look at the bottom of his feet daily, it is unlikely that the beginning of a plantar ulcer will be noticed until it is quite large.

From information gathered on the 40 noncasted patients, it would seem that nonweight-bearing (either by casting or other means) is not an absolute necessity for healing plantar ulcers. In our experience, if a patient is willing to do ulcer care at home, to wear moulded shoes at all times, and to limit walking, it is possible for plantar ulcers to heal. However, the average healing time with a cast is 6 weeks as compared to an average healing time of over 2 months for the noncasted foot. Additionally, noncasted ulcers are more commonly subject to infection.

To meet the needs of the patient who is not hospitalized and who must work or go to school, thereby necessitating more than minimal ambulation and less time for self-care of the ulcer, it is beneficial to have available other means for healing than the traditional application of POP-TCC. Results of several variations used in this clinic are recorded in this paper. As the Scotch Cast-TCC was evaluated on only 3 patients, it is not certain yet to what extent it can replace POP. However, the patients stated that they definitely preferred the lightness of the cast as well as its eliminating the need to use crutches during drying time. The cast is certainly easier to remove than the POP cast and healing time appears about the same. In light of these findings, it would be useful to continue evaluating this type of cast for use in healing plantar ulcerations. Further evaluation of alternative materials and new means of applying them would benefit the current population of leprosy patients who are largely treated in the community and wish to remain ambulatory.

\section{References}

${ }^{1}$ Brand P. Insensitive feet. A practical handbook on foot problems in leprosy. London: The Leprosy Mission, 1981; 31-46.

${ }^{2}$ Birke JA, Sims DS Jr, Buf ord WL. Walking Casts: Effect on plantarf oot pressures. J Rehab Res Dev, 1985; 22: $18-22$.

${ }^{3}$ Pring DJ, Casiebanca N. Simple plantar ulcers treated by below knee plaster and molded double-rocker plaster shoe-a comparative study. Le pr Rev, 1982; 53: 261-4.

4 Warren G. Plaster removal and footcare. Partners. London: Magazine for Paramedical Workers in Leprosy 10 and 11 .

${ }^{5}$ Coleman WC, Brand P, Birke J. The Total Contact Cast: A therapy for plantar ulceration on insensitive feet. J Am Podiatr Med Assoc, 1984; 74: 548-52.

${ }^{6}$ Helm PA, Walker SC, Pullium G. Total contact casting in diabetic patients with neuropathic foot ulcerations. Arch Phys Med Rehabil, 1984; 65: 691-3.

${ }^{7}$ Fischer C. Experience with the treatment of trophic ulcers by plaster casts. Lepr Rev, 1955; 26: $107-11$. 


\section{Bibliography}

Mendis M. Physiotherapy in leprosy. Bristol: John Wright \& Sons Ltd., 1965; pp. 61-75.

Price EW. Plantar Ulcers. In Surgical Rehabilation in Leprosy. Baltimore: Williams \& Wilkins, 1974.

Hice GA et al. The plaster-synthetic cast. J Am Pod Assoc, 1983; 73: 427-31.

Kumar K, Kant M, Belsare RK. Neuropathic plantar ulceration. Ind J Lepr, 1985; 57: 172-7.

Brand P. Management of the insensitive limb. Phy Ther, 1979; 59: 8-12.

Miller JH. Molded Shoes: A discussion. J Am Podiatr Med Assoc, 1984; 74: 462-7.

Shipley DE. Clinical evaluation and care of the insensitive foot. J Am Phy Th Assoc, 1979; 59: 13-18.

Hall OC, Brand PW. The etiology of the neuropathic plantar ulcer. J Am Pod Assoc, 1979; 69: 173-7.

\section{NEWS AND NOTES}

\section{Robert White Fellowships in Immunology}

The British Society for Immunology will consider awarding fellowships, in the memory of Prof essor Robert White, to individuals from developing countries in order to aid or further their education or scientific experience in Immunology. The Society interprets these aims in the broadest possible terms and consideration will be given (for example) to support travel to study in a University or to gain experimental or technical and scientific expertise or for the purchase of books, journals or equipment.

All members of the Society, and particularly those resident overseas, are urged to bring the Robert White Fellowships to the attention of their colleagues. For further details of the scheme, and any enquiries about it, please contact The British Society for Immunology, 11 Hobart Place, London SW1N 0HL.

\section{World Congress of Dermatology, 1989}

This congress is to be held at the Convention Center of Hotel Nacional-Rio, Rio de Janeiro, Brazil on 29 April to 3 May 1989. It is sponsored by International Society of Dermatology: Tropical, Geographic and Ecologic, whose executive president is Prof essor Rubem David Azulay. The following events are being scheduled: 18 courses; 6 special lectures; 7 symposia; 6 forum; 4 special symposia; 72 short communications; 240 mini-case presentations.

For further information: Secretariat Congregare, Marketing de Conferências, Av. Rio Branco, 185, Suite 912. Tel. (021) 533.0105-20040 Rio de Janeiro, RJ, Brazil.

\section{Corrections}

1 Immunological effects of lepromin testing in Sri Lankan population groups I. Effect of repeated lepromin testing. Pinto, MRM, Eriyagama, NB, Pemajayantha, V \& Fish, DG. Lepr Rev, 1987; 58: 119-28.

p. 125, line 2: for 'increase' read 'decrease' and for 'dimunition' read 'increase'.

2 A study of leprosy and other skin diseases in school children in the state of Amazonas, Brazil. Lepr Rev, 1987; 58: $233-7$.

Reference 9 in the above paper has been wrongly cited. It should read

'Int J. Lepr, 1977; 45: 360-3.' 